\title{
Application of Grouting Intensity Number in Spillway Foundation at Jirau HPP/RO
}

\author{
M.B. Lopes, A.P. Assis
}

\begin{abstract}
Brazil has one of the largest hydroelectric parks in the world and important ventures for the world ranking have been executed in the country - to cite the most recent, Jirau and Belo Monte Hydraulic Power Plants (HPP). This emphasizes the importance in the continuous study of techniques and theories commonly used, in order to improve the quality of the projects. This work proposed to implement the Grouting Intensity Number (GIN) methodology for the grouting of waterproofing curtains, through back analysis and estimation of the results of the Jirau HPP foundation treatment. The GIN was chosen from an analysis of curves plotted on a scatter plot as points representing the ratio between the grouting volume (grouting for further analysis) and water (water loss test for estimation) $v s$. the injection pressure. The maximum grouting intensity selected for the Jirau spillway was $50 \mathrm{MPa} \times \mathrm{L} / \mathrm{m}$, which according to the method authors, Lombardi and Deere represents low fracture of the rock mass. Other authors also applied this methodology, finding values higher than in this paper. Therefore, continuity in studies of the application of GIN in projects in Brazil is important to validate its efficiency and to promote progress in this area of dam engineering.
\end{abstract}

Keywords: dams, foundation treatment, GIN methodology, grout curtain.

\section{Introduction}

Implementation of dams in Brazil is part of its history and economic development, having as initial incentive for this construction the Northeast drought and its active participation in the world economic (CBDB, 2011). The country stands out in the implementation of large hydroelectric constructions, known in the whole world by their importance and extension, and the generation capacity of energy in Brazil is open to comparison with the oil production in Saudi Arabia.

In September 2013, the Jirau Hydroelectric Power Plant started its commercial operation, located at the Madeira River, in Rondonia, with installed capacity 3,750 MW. According to Chiossi (2013), Jirau HPP is the fifth in national ranking of capacity and one of the 140 hydroelectric powerplants currently in operation, which represents $77.1 \%$ of Brazil's energy supply (Governo do Brasil, 2018).

The Jirau HPP spillway is a reinforced concrete structure, divided into ten blocks and with a flow rate of $82,600 \mathrm{~m}^{3} / \mathrm{s}$. The safety of concrete dams can be achieved by controlling the uplift forces and the displacements provided by induced loads that are transferred to the foundation, and Oliveira (2002) states that the major stability issue is the uplift effect. To reduce the influence of this effect in the concrete dam base, foundation treatments can be used, including grout curtain and drain holes. In 1961, Arthur Casagrande presented the "First Rankine Lecture" at the Institution of Civil Engineers, relating the prejudices and opinions about the efficiency of grouting under uplift effects (Oliveira, 2002), which since then has generated conflicts among designers.

The first works with grout curtain were carried out in France, in 1802, by the engineer Charles Bérigny, who indicated this alternative for foundation consolidation of Dieppe lock. In Brazil, the first use of the methodology was promoted by IPT - Institute for Technological Research - in Barra Bonita dam, in Tiete River, in the 1950s (Levis, 2006). The most utilized criteria of execution in the country was created by Houlsby in 1976 and updated in 1990, that considers the injectability of the cement grout in rock mass vs. pressure, using the "Split-Spacing" for drilling the grouting holes. This opening system was proposed by Nonveiller in 1979 and prescribes that the initial space of the holes must be chosen considering that the grouting regions do not overlap initially, following the drilling of primary, secondary and tertiary holes (Gama, 2012). For Houlsby (1990), the grouting pressure must be maintained for fifteen minutes until setting is reached, when the grout is stabilized and gains resistance. Brandão (2014) emphasizes that the setting concept was idealized for unstable grouts, wherein the rheology is susceptible and variable, and can have segregation and sedimentation. For Warner (2004), the use of unstable grouts is outdated and the set should be any point when there is no more absorption of cement grout. These discussions about the grouting pressures to be adopted and its flow encouraged Lombardi \& Deere (1993) to develop a methodology that aims to systematize the execution of grout curtains, named as Grouting Intensity Number (GIN).

Marieli Biondo Lopes, M.Sc., Professor, Universidade Comunitária da Região de Chapecó, Chapecó, SC, Brazil. e-mail: marybiondo@ hotmail.com. André Pacheco Assis, Ph.D., Professor, Universidade de Brasília, Brasília, DF, Brazil. e-mail: aassis@ unb.br.

Submitted on March 22, 2019; Final Acceptance on February 24, 2020; Discussion open until September 30, 2020.

DOI: $10.28927 /$ SR.432171 
The GIN purpose is to standardize, define the dosage for grout injection, using a unique mix that considers the limited penetration due to the size of the cement particles and, thus the finer the cement particle, the larger the effectiveness of grout injection (Cruz et al., 2009). According to Carvalho et al. (2003), Mascarenhas de Moraes HPP was the first development in Brazil to use GIN as a grouting treatment procedure and there are technical advantages of this approach when compared to the conventional one, so its use in other projects would increase quality and reliability efficiency. Therefore, this research aims to describe implementation of this procedure at Jirau HPP, to compare the results with the literature, and to point out the benefits that the application of the method can bring to other future dam projects.

\section{GIN Method - Grouting Intensity Number}

According to Gama (2012), the grouting behavior is divided in function of two types of fluids: Newtonian and Binghamian. Newtonian fluids are characterized by a force needed to move the liquid, which is related with the dynamic viscosity. In Binghamian fluids, the cohesion or thixotropy exists in addition to the dynamic-plastic viscosity, as shown in Fig. 1, where $C=$ cohesion; $\eta=$ viscosity for Binghamian fluids; $\eta$ ' = viscosity for Newtonian fluids; $\tau=$ shear stress; $\frac{d v}{d t}=$ shear rate.

Lombardi \& Deere (1993) state that the difference between them is that in Newtonian fluids the viscosity governs the penetration velocity and designates their rheological behavior, and in Binghamian fluids, in addition to the viscosity, the cohesion is a resistance to creep and governs the maximum distance of penetration. Figure 2 presents a graph (Houlsby, 1990) where it is possible to verify the cement grout behavior in relation to the dosage, when analyzed in cohesion and viscosity terms. Thicker grouts $(w / c$ ratios of 0.6:1 and 0.7:1) have a shear stress intercept (cohesion) greater than fine particles ( $w / c$ ratios of $1: 1$ and $3: 1$ ), but the viscosity or percolation distance are less than the

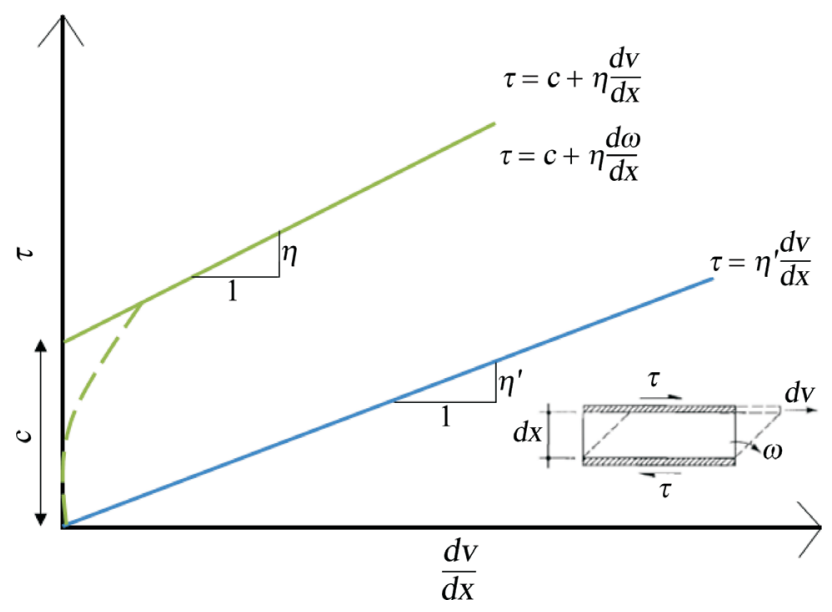

Figure 1 - Rheological Models: 1) Newtonian; 2) Binghamian. finer particles. For closed discontinuities, higher $w / c$ ratios are indicated due to their viscosity. In wider-aperture discontinuities, thicker grouts are used, with a lower $w / c$ ratio.

The grouting pressure is also an important factor, where Levis (2006) cites two trends: American and European. The American System defends the use of low pressures, calculated on the basis of $25 \mathrm{kPa} / \mathrm{m}$ (as adopted In the Jirau HPP project). In the European procedure, the pressure factor is $100 \mathrm{kPa} / \mathrm{m}$, which characterizes the adoption of high pressures. The disadvantage of using high pressures is the possibility of causing the elastic opening of the discontinuities and this may be irreversible. The elastic opening is beneficial, but high pressures can open discontinuities that were sealed, becoming harmful (Marques Filho, 1986 apud Levis, 2006).

The discussions about the grouting pressures that will be adopted and their fluidity encouraged Lombardi \& Deere (1993) to develop the GIN methodology - Grouting Intensity Number, with the purpose of defining the grout dosage, using a unique mix and that considers the penetration limited by the size of cement particles. According to the authors, beyond the adoption of a single dosage of grout in all the injection process, the pressure increases gradually in accordance with the grout penetration in the fractures, and it can monitor the pressure, flow velocity and injectability by integrated system with real time data acquisition. So, GIN represents the product of grouting volume ( $V$ in $\mathrm{L} / \mathrm{m}$ ) at $1 \mathrm{~m}$ and the corresponding grouting pressure ( $p$ in $\mathrm{kPa}$ ), given by:

$$
G I N=p \times V
$$

To Lombardi \& Deere (1993), the GIN main characteristic is the limitation of grouting pressure, preventing excessive pressure and grout volumes that can cause hydraulic fractures or the lifting of foundation mass, as shown in Fig. 3. The GIN is supported due to the traditional waterproofing methods of rock foundations having been based

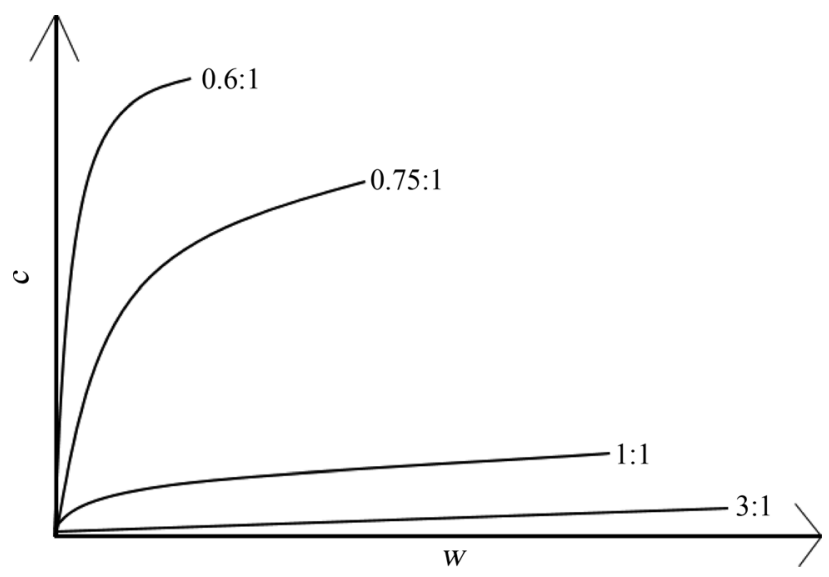

Figure 2 - Comparison of cement grout thixotropy for different $w / c$ ratios by grout weight. 

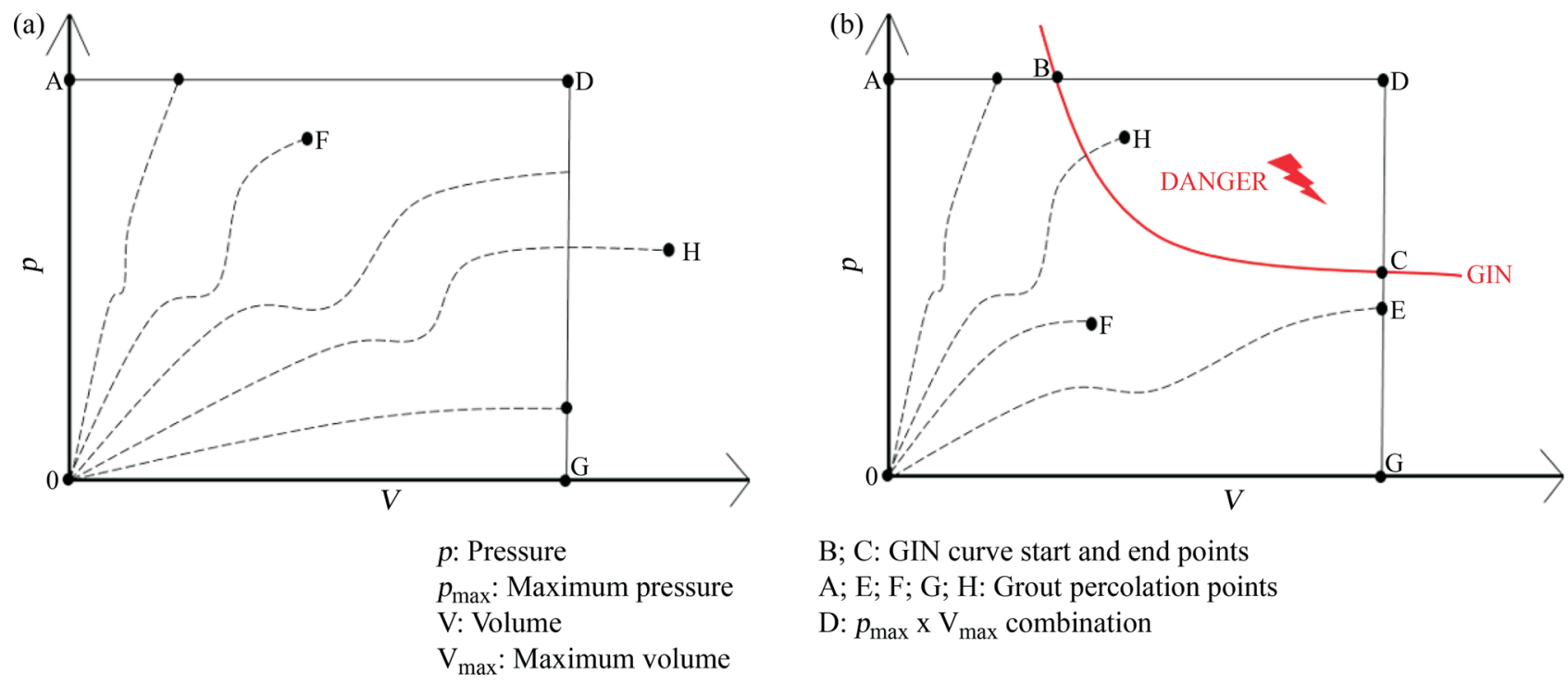

B; C: GIN curve start and end points

A; E; F; G; H: Grout percolation points

D: $p_{\max } \times \mathrm{V}_{\max }$ combination

Figure 3 - Limits imposed on the injection process a) Houlsby Method; b) GIN method.

on empirical principles, institutional and professional experiences that conducted to dogmatic beliefs (op. cit.).

The GIN methodology requires that once selected the intensity level to be grouted, this number is maintained not only for the filling of fractures easily injected (with large volume of absorption and low pressure), but also for the thinner fractures (with lower grout absorption and larger adopted pressure), maintaining the GIN constant. Lombardi and Deere (1993) defined guide curves used as reference parameters for the adoption of intensities, in which wider discontinuities require an intensity of $250 \mathrm{MPa} \times \mathrm{L} / \mathrm{m}$. Finally, in cases characterized by closed and extremely closed cracks, the pressure increases with a small increase in grout volume $(G I N<150 \mathrm{MPa} \times \mathrm{L} / \mathrm{m})$.

Figure 4 indicates that the maximum limit for volume and pressure needs to be defined, before the elaboration of the GIN curve. According to Gama (2012), point $F$ is the intersection between curve 2 and curve 1, representing the fi-

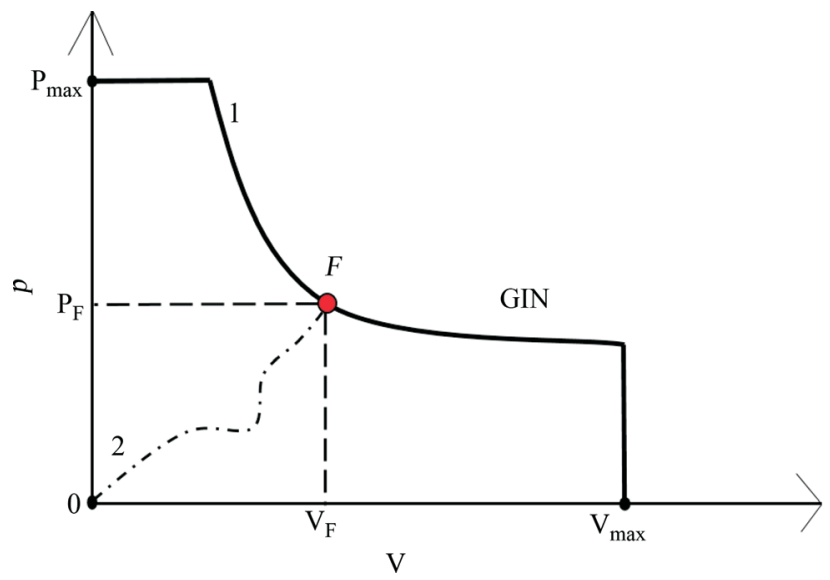

Figure 4 - Representation of the GIN curve. nal values of pressure and absorption, indicated as the GIN to be adopted.

Lombardi (1996) defined that the maximum pressure is conditioned by the hydraulic pressure that the rock mass is submitted to, varying between twice or three times this magnitude and the maximum volume by the injectability factors determined in the subsoil survey phase. The author compared the traditional method and the GIN, concluding that:

a) As regards the grouting dosage, using a thicker and more stable grout in the GIN method achieves the same objective as the traditional methods;

b) The mix cohesion, due to the use of lower $w / c$ relations, is maintained constant during the entire injection process and, therefore, the setting concept became unnecessary;

c) The final grouting pressure in the GIN methodology remains lower than in the traditional method, reducing the risk of hydraulic fractures in the rock mass.

\section{Jirau Hydroelectric Powerplant}

Jirau HPP was constructed $120 \mathrm{~km}$ away from the capital of Rondonia, Porto Velho, near to Jaci Paraná district, in an island of Madeira River, named Ilha do Padre. According to the HPP has generation capacity of $3,750 \mathrm{MW}$, being capable to supply more than 10 million houses.

The Jirau HPP complex comprises concrete, soil, soil and rockfill, and rockfill with asphalt core structures. Concrete structures encompass two powerhouses, one placed in the right bank of the river with 28 bulb turbines, and the second in the left bank with 22 turbines, summing up 50 generating units with $75 \mathrm{MW}$. Figure 5 presents the satellite image of the HPP location. 

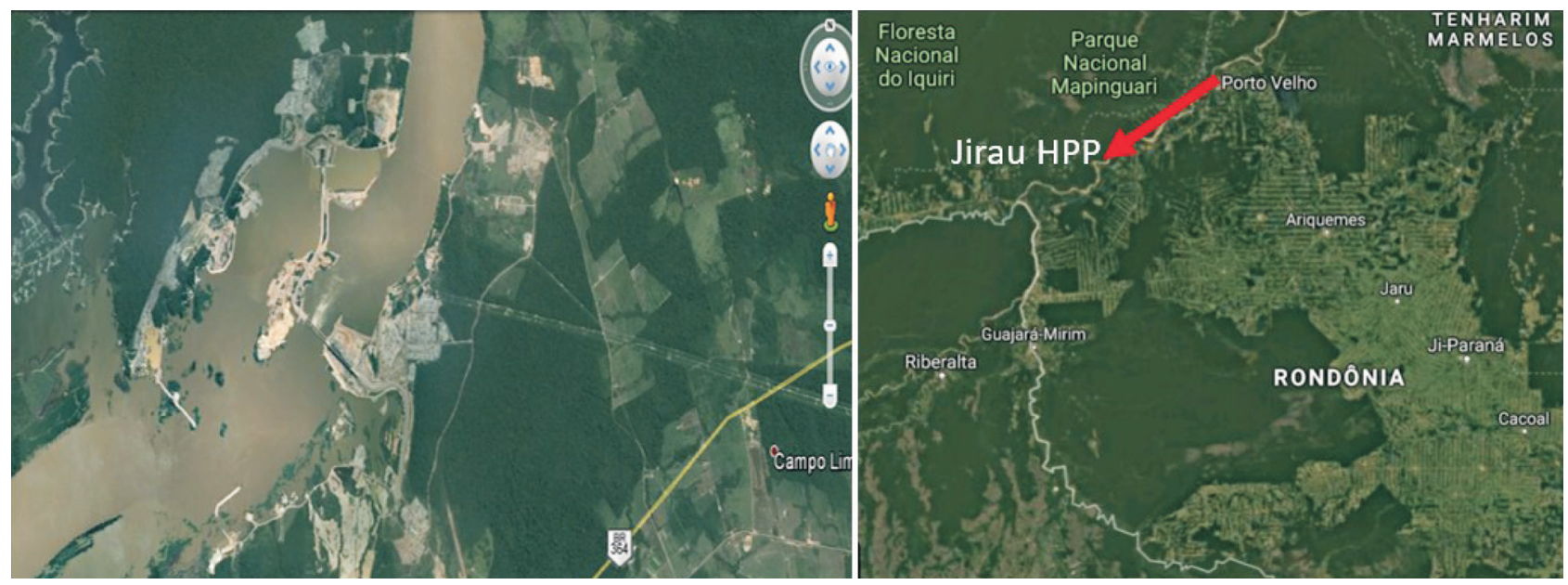

Figure 5 - Aerial view of the execution of the development (Google Earth, 2014).

In the region, it is possible to find granites of the São Lourenço-Caripunas Intrusive Suite, beyond the conglomerate of soils and rocks of the Palmeiral Formation and sediments of the fluvial terrace in the Quaternary Jaciparaná Formation.

In the site investigation carried out along the dam longitudinal axis, the existence of rock masses such as granites, rhyolites and diabase were confirmed, where the granites and rhyolites belong to a batholith with an approximate area of $3,000 \mathrm{~km}^{2}$, responsible for the waterfalls of Santo Antônio Teotônio do Inferno (axis of the Ilha do Padre) and Jirau.

The granite of the spillway foundation is very fractured and little weathered on the surface, identifying discontinuities Zx (vertical), Ix (inclined) and Dx (subhorizontal) parallel to the river flow.

The foundation treatment executed in the concrete structures of the Jirau complex was composed of grouting lines and deep drains, following the conventional methodology of Houlsby (1990) and the opening of holes using the split-spacing method proposed by Nonveiller in 1970. For the spillway, three lines for a deep treatment were designed. The upstream line has primary, secondary and tertiary holes, spaced $3 \mathrm{~m}$, with a vertical depth of $20 \mathrm{~m}$ and dip of $20 \%$ upstream. The central and downstream lines were formed by possible holes, opened when the required holes exceeded a grout absorption of $30 \mathrm{~kg} / \mathrm{m}$, based on design criteria.

The absorption of $30 \mathrm{~kg} / \mathrm{m}$ or less rates the rock mass as with low permeability, which corresponds to a permeability coefficient k from $10^{-5}$ to $10^{-4} \mathrm{~cm} / \mathrm{s}$, considered satisfactory for the treatment effectiveness. The design criteria corroborate with the indication of treatment necessity pointed out by Costa (2012), where the author indicates the injection along two or three lines in cases where the hydraulic conductivity of the rock mass is between $k=10^{-5}$ to $5 \times 10^{-4} \mathrm{~cm} / \mathrm{s}$.
Hole drilling was carried out by a rotary-percussive drilling tool with injection of air and water simultaneously, to prevent drilling debris block the entrance and percolation of cement grout, as mentioned in other cases by Marques and Filho (1986 apud Levis, 2006). It is used the ascending form of treatment, where it is drilled the entire hole and then, it is grouted in stretches with double packers, being the fastest process for construction with tight deadlines. The grouts used in the treatment was conventional grouts (cement and water), with initial dosage which $w / c$ of $0.7: 1$ and thickened in the end to $0.5: 1$.

\section{Methodological Procedures}

The confection of GIN curves of the spillway blocks of Jirau HPP was made in two ways to compare the results and selection of the adopted GIN: the first by back analysis of the obtained results with the grouting curtain in the original design and, the second, by estimation from the results of Water Loss Tests (in Portuguese - EPA), executed in the primary holes with $24 \mathrm{~m}$ spacing (Oliveira et al., 1975).

To determine the GIN curve of each spillway block by back analysis, the results of the conventional (Houlsby) method were converted to values of grout pressure $\mathrm{x}$ volume for the GIN method $(\mathrm{kP} \times \mathrm{L} / \mathrm{m})$, and those values were plotted in a dispersion graph. The pressure is maintained with the same values indicated in grouting bulletins, converting only the unit of measurement to $\mathrm{kPa}$. The cement consumption $(w / c$ ratios of $0.7: 1$ and $0.5: 1)$ collected from the bulletins as $\mathrm{kg} / \mathrm{m}$ was converted into $\mathrm{L} / \mathrm{m}$, considering the CP IV-32 cement unit weight of $2,900 \mathrm{~kg} / \mathrm{m}^{3}$.

After the cement consumption definition for each grout dosage, the final volume of the mix was obtained in $\mathrm{L} / \mathrm{m}$. As the GIN method adopts a single grout pressure, it is used the criteria of weighted volume, transforming the grout into a homogeneous fluid.

To determine the GIN curves by estimation, the results of water absorption in the primary hole, are used the 
water volume absorbed by the hole is indicated as cement grout volume to be injected $(\mathrm{L} / \mathrm{m})$ and the test pressure as injection pressure $(\mathrm{kPa})$.

The obtained results for the two types were disposed in a dispersion chart (pressure $\mathrm{x}$ volume) and hyperbolic curves with random intensities were inserted in those graphs to verify proximity between those points and the predetermined GIN curves, choosing for each block the best intensity $(\mathrm{kPa} \times \mathrm{L} / \mathrm{m})$. For the curves, the limits of volume and pressure were also determined in the direction of the volume, adopting an absorption of cement grout or water, and the pressure, the criteria cited by Lombardi (1996), two or three times the rock mass is submitted. For the mandatory (upstream) and possible (downstream) hole lines the theoretical grouting dosage was considered, assessing:

a) Total consumption of the grout with $w / c$ ratio of $0.7: 1$ in the mandatory holes;

b) Total consumption of the grout with $w / c$ ratio of $0.5: 1$ in the mandatory holes;

c) Consumption of water $\left(w_{0.7: 1} ; w_{0.5: 1}-\mathrm{L}\right)$ and cement $\left(c_{0.7: 1}\right.$; $c_{0.5: 1}-\mathrm{kg}$ ) for each dosage in the line of mandatory holes;

d) Theoretical grout dosage given by:

$$
\frac{w}{c}=\frac{w_{0.71: 1}+w_{0.5: 1}}{c_{0.71: 1}+c_{0.5: 1}}
$$

e) The same was evaluated for the possible grouting lines.

\section{Results and Discussion}

About the grout volume of cement and water, the values found in the grouting bulletins and EPA tests of the curtain in the Jirau HPP ranged from 20 to $800 \mathrm{~L} / \mathrm{m}$ along the foundation of the spillway blocks. The determination of the maximum pressure magnitude, using the concept cited by Lombardi (1996), adopted:

a) Water specific weight $\left(\gamma_{w}=9.81 \mathrm{kN} / \mathrm{m}^{3}\right)$ multiplied by the height of water column $(\mathrm{Hw})$, and in this case the normal maximum of the upstream tank of $28 \mathrm{~m}$, obtaining hydraulic pressure $\left(\sigma_{w}\right)$ equal to $275 \mathrm{kPa}$.

b) The maximum pressure greater than or equal to three times the hydraulic pressure $\left(p_{\max }=3 \times \sigma_{w}\right)$ resulted in
$825 \mathrm{kPa}$, which was discarded because all results of the grouting curtain executed in Jirau were below this one. Thus, the adopted pressure was $2.5 \times \sigma_{w}$ $\left(p_{\max }=700 \mathrm{kPa}\right)$.

From this, the curves confection was divided in those two mentioned groups in grout 4 for each block in the spillway, as detailed in Sections 5.1 and 5.2. Figure 6 shows the spillway scheme and the position of the studied blocks. The results for each group are presented in Table 1.

\subsection{GIN curves elaborated by back analysis}

Figures 7 and 8 present the dispersion graphs and random GIN curves for three blocks of the spillway structure that were highlighted in those results in accordance to Table 1.

In Fig. 7, it is possible to observe that the VT-02 Block is in an area of water and cement grout low absorption, with maximum values less than $15 \mathrm{~L} / \mathrm{m}$. So, the $G I N$ curves plotted in the dispersion graph tend to approach the highest number of points, with intensities varying between $0.8 \mathrm{MPa} \times \mathrm{L} / \mathrm{m}(G I N 1), 1.5 \mathrm{MPa} \times \mathrm{L} / \mathrm{m}(G I N 2)$ and $2.5 \mathrm{MPa} \times \mathrm{L} / \mathrm{m}($ GIN 3$)$.

As the curves were randomly plotted, the chosen curve was the closest one to the plotted points and best represents the situation - for VT-02 (according to Table 1), with GIN 2 intensity $1.5 \mathrm{MPa} \times \mathrm{L} / \mathrm{m}$. However, in block VT-06 (Fig. 7b) there was a higher grout consumption, so there was a greater dispersion of the consumption points, for the same pressure adopted. In addition, the cement grout absorption reached volumes close to $600 \mathrm{~L} / \mathrm{m}$, due to its location in a region with greater presence of discontinuities (observed in the EPA results, injection and geologicalgeotechnical mapping).

However, in the same Fig. $7 \mathrm{~b}$ it can be verified that three points are distant from the results in other sections of holes in the VT-06 block, and the random GIN curves stayed away from those points too. Thus, for VT-06, the highest intensity curve (GIN 3, as shown in Table 1) was adopted to consider the high consumption of grout in this region, as a consequence of wider discontinuities.

For the VT-07 block (Fig. 8) the highest injection intensity was adopted, presenting maximum volume

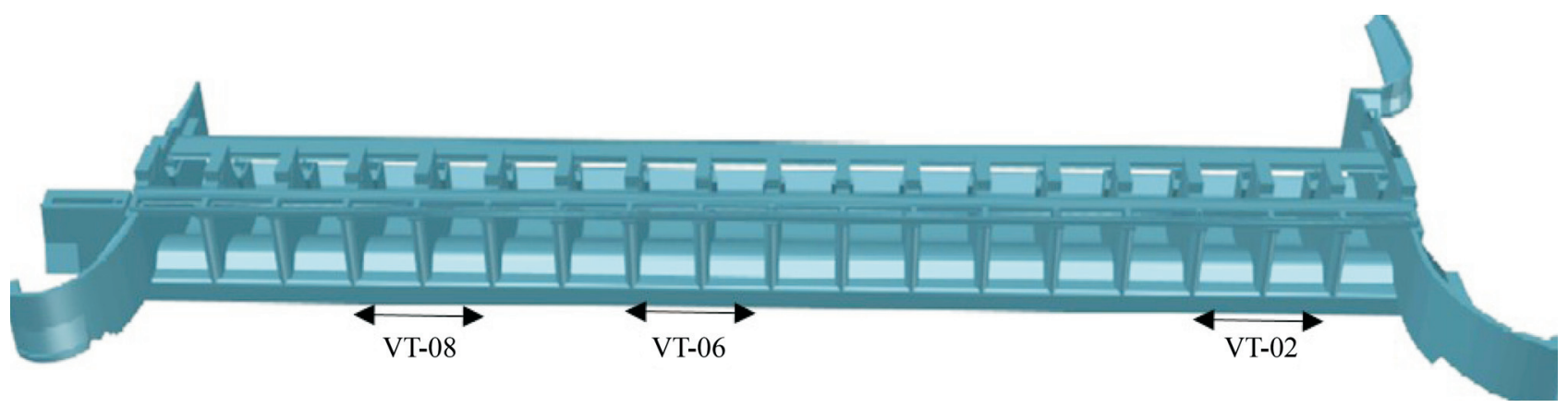

Figure 6 - Spillway structure. 
Table 1 - Results of GIN curves adopted for each block and the order of spillway holes.

\begin{tabular}{|c|c|c|c|c|c|c|}
\hline \multirow[t]{2}{*}{ Block } & \multicolumn{3}{|c|}{ GIN curve by back analysis } & \multicolumn{3}{|c|}{ GIN curve by estimate } \\
\hline & $p_{\max }(\mathrm{kPa})$ & $v_{\max }(\mathrm{L} / \mathrm{m})$ & $\begin{array}{c}\text { GIN }(\mathrm{MPa} \times \\
\mathrm{L} / \mathrm{m})\end{array}$ & $p_{\max }(\mathrm{kPa})$ & $v_{\max }(\mathrm{L} / \mathrm{m})$ & $\begin{array}{c}\text { GIN }(\mathrm{MPa} \times \\
\mathrm{L} / \mathrm{m})\end{array}$ \\
\hline VT-01 & 700 & 20 & 2 & 700 & 200 & 12 \\
\hline VT-02 & 700 & 20 & 1.5 & 700 & 150 & 18 \\
\hline VT-03 & 700 & 40 & 1.5 & 700 & 30 & 1 \\
\hline VT-04 & 700 & 50 & 1.5 & 700 & 40 & 3 \\
\hline VT-05 & 700 & 350 & 2 & 700 & 600 & 30 \\
\hline VT-06 & 700 & 600 & 3 & 700 & 100 & 7 \\
\hline VT-07 & 700 & 750 & 7 & 700 & 500 & 30 \\
\hline VT-08 & 700 & 450 & 3 & 700 & 600 & 50 \\
\hline VT-09 & 700 & 250 & 2.5 & 700 & 800 & 20 \\
\hline VT-10 & 700 & 160 & 2 & 700 & 380 & 8 \\
\hline
\end{tabular}

higher than $700 \mathrm{~L} / \mathrm{m}$. Unlike VT-06 (Fig. 7b), in the current block, the points were dispersed more uniformly until achieving the maximum volume. Consequently, the adopted GIN curves considered higher magnitudes, varying between $0.5 \mathrm{MPa} \times \mathrm{L} / \mathrm{m}($ GIN 1$), 7 \mathrm{MPa} \times \mathrm{L} / \mathrm{m}$ $(G I N 2)$ and $15 \mathrm{MPa} \times \mathrm{L} / \mathrm{m}(G I N 3)$, and thus, adopting the average number. The most significant discontinuities were found between blocks VT-06 and VT-09,
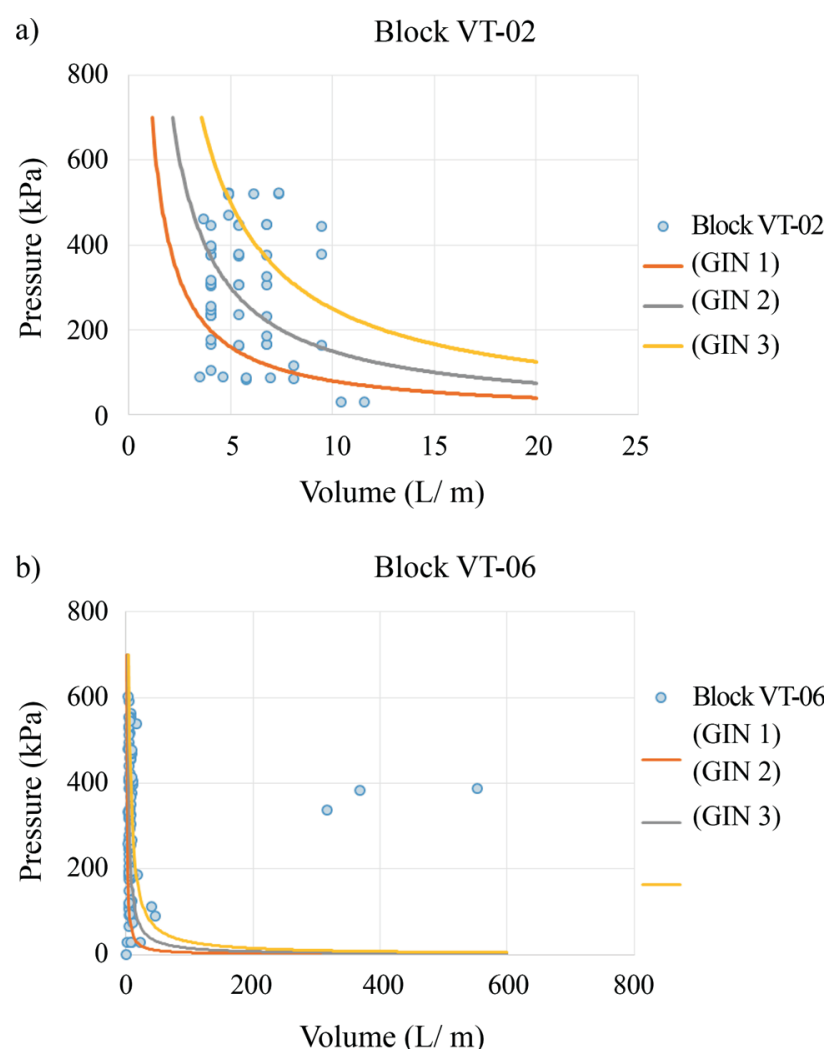

Figure 7 - GIN curves determined by back analysis: a) VT-02 Block; b) VT-06 Block. forming the main treatment region in the foundation structure.

\subsection{GIN curves elaborated by estimation}

Figure 9 presents the GIN curves determined by estimation for the VT-02 and VT-08 blocks. In Fig. 9a, it is possible to verify that the maximum volumes reach $150 \mathrm{~L} / \mathrm{m}, 7.5$ times higher than the volumes obtained by back analysis (Fig. 7a).

For block VT-02, the GIN curves plotted in the dispersion graph have magnitudes of $2 \mathrm{MPa} \times \mathrm{L} / \mathrm{m}(G I N 1)$, $18 \mathrm{MPa} \times \mathrm{L} / \mathrm{m}(G I N 2)$ and $35 \mathrm{MPa} \times \mathrm{L} / \mathrm{m}($ GIN 3$)$, pointing out that the higher intensity of grouting for VT-02 by back

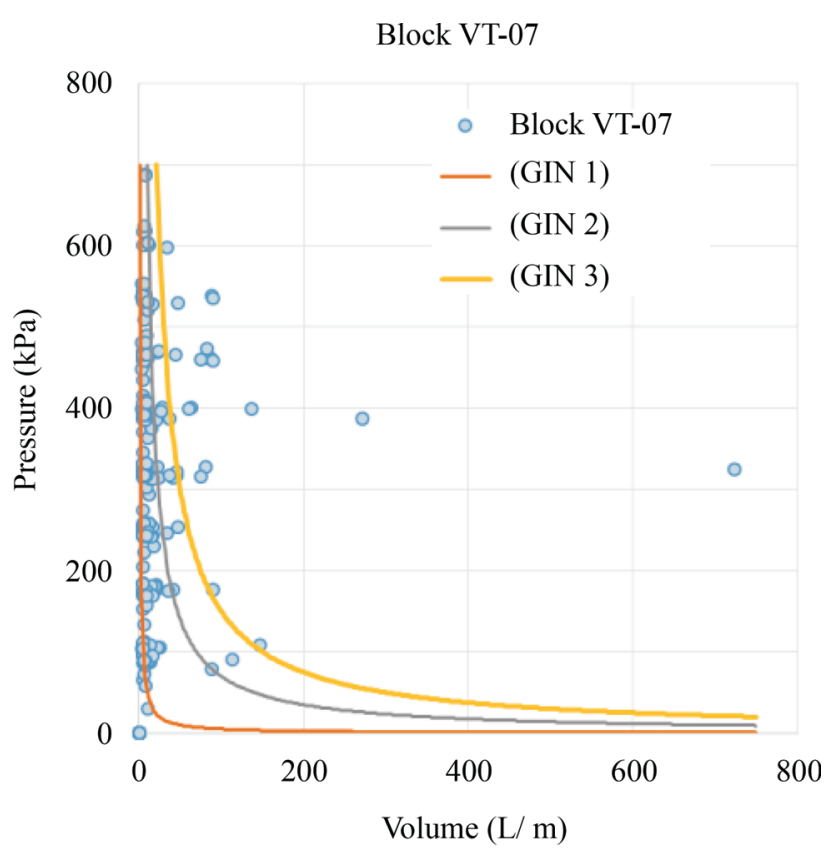

Figure 8 - GIN curves determined by back analysis for VT-07 Block. 
a)

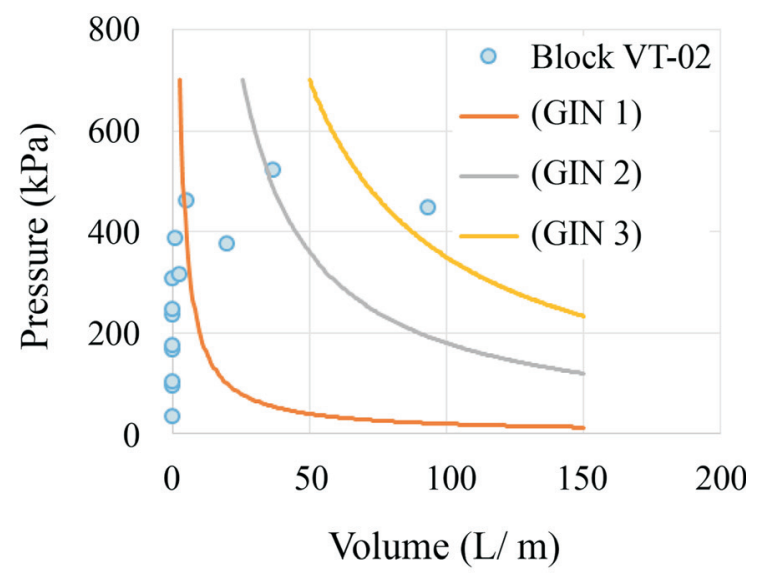

b)

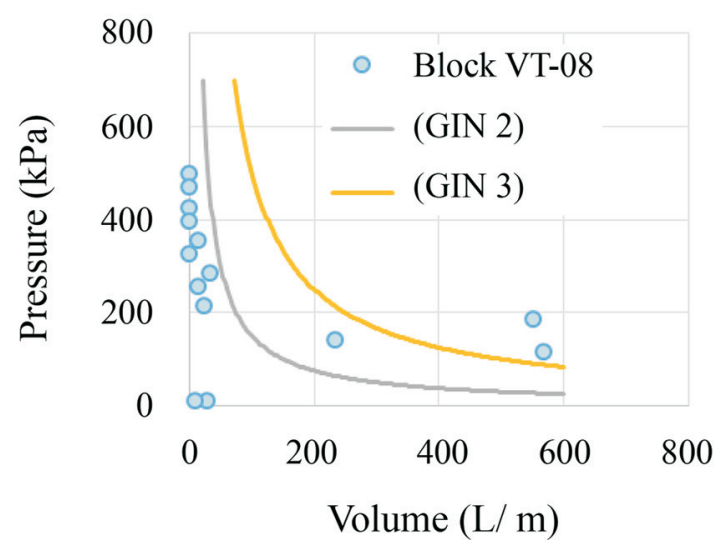

Figure 9 - GIN curves determined by estimation: a) Block VT-02; b) Block VT-08.

analysis was $2.5 \mathrm{MPa} \times \mathrm{L} / \mathrm{m}$. In the case of the estimated results, this difference is due to the fact that discontinuities are not filled with grout and facilitate water seepage.

Figure $9 \mathrm{~b}$ presents the curves of the VT- 08 block, with maximum volumes up to $600 \mathrm{~L} / \mathrm{m}$ like the VT-06 block (Fig. 7b). In this graph, one of the GIN curves was rejected due to the small dispersion of the plotted points, being very close to the axis. Two curves were then chosen, one with $15 \mathrm{MP} \times \mathrm{L} / \mathrm{m}(G I N 2)$ and the other with $50 \mathrm{MPa} \times \mathrm{L} / \mathrm{m}($ GIN 3$)$. The intensities adopted for blocks VT-02 and VT-08 are expressed in Table 1, as well as for the other blocks of the spillway.

In Table 1, for the curves obtained by estimation, the highest intensity adopted in the foundation was in block VT-08 (50 MPa $\times \mathrm{L} / \mathrm{m})$, unlike the curves made by back analysis, where the largest GIN was applied in VT-07 $(7 \mathrm{MPa} \times \mathrm{L} / \mathrm{m}$ ). VT-08 was the block that presented the largest number of discontinuities during the geologicalgeotechnical investigation and EPA tests, being these fractures identified by the highest water consumption. During the cement grouting activity, possible holes (LC and LJ) were opened in greater quantity than in VT-07, which generated points in the dispersion graphs with smaller volumes, shifting the hyperbolic curves closer to the axes, and consequently reducing the product of the pressure with the volume.

\subsection{Choice of GIN curve}

In each block studied, from the three plotted curves, the one that most closely approximated the graph scatter points was chosen. Comparing the GIN for the cases obtained by back analysis and estimation (Table 1), a great difference is observed in the results, motivated by what was explained in Section 5.2. However, for both analyses, the maximum pressure is the same and the maximum volumes are similar, but the pressure-volume GIN result reaches a difference of up to 16 times. The result of the GIN for this work is related not only to the limit numbers of the curves (pressure and volume), but also to the location of the hyperbolic curves adopted, so that they could interconnect the points of dispersion.

Figure 10 compares the curves generated by back analysis and estimation for the VT-03 block. It shows that the GIN curves by back analysis and estimation have the same magnitude, being the curve determined by retro analysis (Fig. 10a), the one with the highest intensity $(1.5 \mathrm{MPa} \times \mathrm{L} / \mathrm{m})$ when compared to that by estimation (Fig. 10b), which resulted in an intensity of $1 \mathrm{MPa} \times \mathrm{L} / \mathrm{m}$.

As already mentioned, the curves are adequate for the dispersion points and therefore the intensity varies for each block, which can be seen in Fig. 10a where there are more pressure $\mathrm{x}$ volume points based on grouting hole results. On the other hand, in Fig. 10b, since the number of primary holes with EPA tests in the block is lower, the points are more adjusted and located in the same region. Again, it is proved that for this research, the intensity of the curves depends on the dispersions and not only on the limits of pressure and volume.

According to the guide curves proposed by Lombardi \& Deere (1993), for wider-aperture discontinuities, an intensity of more than $250 \mathrm{MPa} \times \mathrm{L} / \mathrm{m}$ (or 2,500 bar $\times \mathrm{L} / \mathrm{m}$ ) is used, while for the most tight discontinuities, intensities below $50 \mathrm{MPa} \times \mathrm{L} / \mathrm{m}$ (or 500 bar $\times \mathrm{L} / \mathrm{m}$ ) are employed. Comparing the curves that guide the results of this research (Table 1), it can be concluded that the intensities determined by the estimation method are close to those mentioned by Lombardi \& Deere (1993), and it can be stated that the foundations of the Jirau Spillway have tight discontinuities (closed) and, therefore, the default would be the adoption of low GIN values.

However, it is worth mentioning that the method proposed by Lombardi \& Deere (1993) was used in countries such as Argentina, Austria, Ecuador, Mexico, Turkey and Portugal, with different grouting processes from those adopted in Brazil, including aspects of permeability tests of 

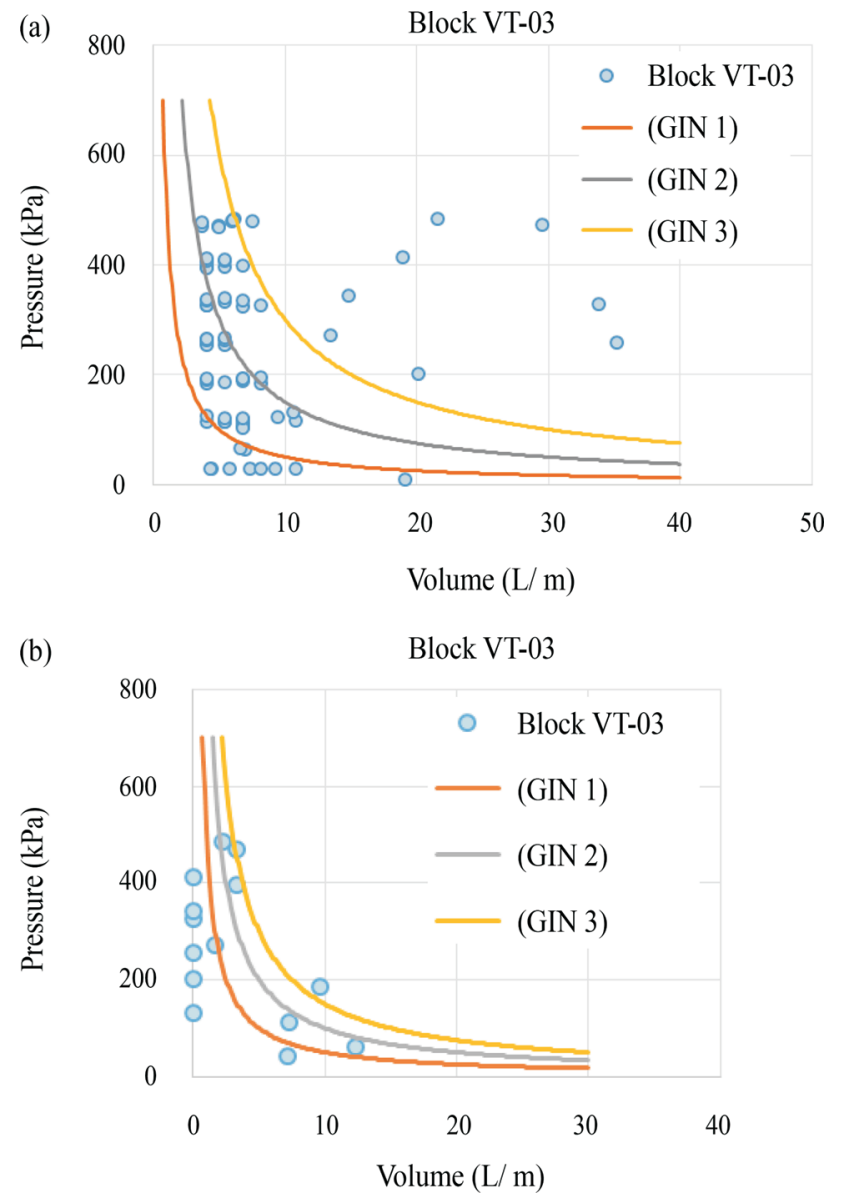

Figure 10 - GIN curves determined for block VT-03: a) Back analysis; b) Estimation.

the rock mass, in which the EPA test is used in Brazil, and in other countries, Lugeon tests.

The impregnation and determination relationship of the standard curves are based on the results of Lugeon, where $1 \mathrm{Lu}$ (Lugeon unit) is equivalent to a permeability coefficient of $10^{-5} \mathrm{~cm} / \mathrm{s}$. The pressures adopted in Europe consider values greater than the American practices, and this is directly related to the local rock mass. Lombardi \& Deere (1993) emphasize in their work that the GIN improves with the execution of the activity, whereby the intensity can be increased or decreased as the need arises. This makes the study of the application of the method in other countries renew the theoretical parameters, and each work performed provides a database for the following, giving greater reliability to the method.

At the Mascarenhas HPP, Oliveira et al. (2001) report that the intensity adopted in the project was $100 \mathrm{MPa} \times \mathrm{L} / \mathrm{m}$, with a maximum pressure of $2.2 \mathrm{MPa}$ and a maximum volume of $150 \mathrm{~L} / \mathrm{m}$. The GIN number of this project corroborates those presented by Lombardi \& Deere (1993), and distance themselves from those found in this research. In the case of Mascarenhas HPP, the pressure used is three times greater than the maximum pressure used in the Jirau HPP, and in this case it is not possible to compare the two cases, where the quality of the rock mass is fundamental for this decision making.

Gama (2012) studied the application of the GIN in the Apartadura Dam, located near the city of Portalegre (Portugal). The author has established GIN curves by backanalyzing the grouting curtain cement consumption in the original design, which found intensity numbers between $20.5 \mathrm{MPa} \times \mathrm{L} / \mathrm{m}$ and $35.5 \mathrm{MPa} \times \mathrm{L} / \mathrm{m}$, with maximum volume of $350 \times \mathrm{Lm}$ and maximum pressure of $600 \mathrm{kPa}$. The limits of the curves adopted by the author are similar to those found in this paper, but the final product distances itself from the results obtained through back analysis, due to the interpolation of the dispersion points.

Finally, the choice of the GIN curves was performed for the sake of safety, adopting the method of determination that presented smaller results, that is, the curves obtained by back analysis. As the GIN is adapted during the execution process, it is understood that at the beginning of the activity, the intensity is higher and as the grout fills the discontinuities, the need for larger numbers is considerably reduced. This decision was also based on the results of the analysis of the deep treatment performed in the Jirau HPP spillway and explained by Lopes \& Assis (2016), which affirmed that the rock mass, even without grouting treatment, has fair hydraulic characteristics, with a permeability coefficient of $10^{-4} \mathrm{~cm} / \mathrm{s}$ in the region of higher water absorption (VT-06 to VT-09). Thus, since the foundation does not have discontinuities with large apertures and low hydraulic conductivity, there is no need to induce a high injection volume, or to add high pressure, which would result in plastic opening of the existing cracks or hydraulic fracturing.

\subsection{Dosage determination of theoretical grout}

Tables 2, 3 and 4 present the water $(w)$ and cement $(c)$ consumption, also the volume of homogeneous grout $(w / c)$, determined by Eq. 2 .

Tables 2 and 3 show the water and cement requirements during the grouting of mandatory (LM) and occasional LC and LJ holes, and Table 4 is the unification of

Table 2 - Results of grout cement quantities for each dosage original project.

\begin{tabular}{lccc}
\hline Holes & $c_{0.7}(\mathrm{~kg})$ & $c_{0.5}(\mathrm{~kg})$ & $c_{\text {Total }}(\mathrm{kg})$ \\
\hline Mandatory & $32,849.84$ & $6,323.46$ & $39,173.30$ \\
Occasional & $28,704.34$ & $3,105.54$ & $31,809.88$ \\
\hline
\end{tabular}

Table 3 - Results of the water volume for each dosage.

\begin{tabular}{lccc}
\hline Holes & $w_{0.7}(\mathrm{~L})$ & $w_{0.5}(\mathrm{~L})$ & $w_{\text {Total }}(\mathrm{L})$ \\
\hline Mandatory & $32,849.84$ & $6,323.46$ & $39,173.30$ \\
Occasional & $28,704.34$ & $3,105.54$ & $31,809.88$ \\
\hline
\end{tabular}


Table 4 - Results of $w / c$ relations of theoretical grout.

\begin{tabular}{lccc}
\hline Holes & $w_{0.7}+w_{0.5}(\mathrm{~L})$ & $c_{0.7}+c_{0.5}(\mathrm{~kg})$ & $w / c$ \\
\hline Mandatory & 26,157 & 39,173 & 0.67 \\
Occasional & 21,646 & 31,810 & 0.68 \\
\hline
\end{tabular}

consumption to determine a single and homogeneous grout as one of the main objectives of the GIN methodology. After homogenization, the dosages were similar for both hole types, considering in this case, $w / c$ ratio of $0.68: 1$.

The main dosage used in the curtain of the original project of Jirau HPP was a $w / c$ ratio of $0.7: 1$, (that represents $80 \%$ of the cement consumption compared with the $w / c$ ratio of $0.5: 1$ ), and the results found by homogenization corroborates this adoption. The prerogative of GIN is that, instead of thickening the grout, the process continues with the same water / cement ratio, changing only the magnitude of the pressure and the volume of grout injected. According to Brandão (2014), for the application of the GIN in projects, these should adopt stable grouts with higher cohesion values or thicker mixtures that approach the Binghamian behavior, as explained in Fig. 2. Therefore, the dosage used in the original design and that homogenized by Eq. 2 and detailed in Table 4 can be used in the application of the GIN method of injection.

\section{Conclusions}

The objective of this work was to evaluate the application of the GIN methodology in the Jirau HPP spillway foundation, through the data and results obtained during the construction of the project. The original foundation treatment project was executed according to the conventional methodology proposed by Houlsby (1990), with drilling of split-spacing holes and low pressures according to the American school. The choice of injection intensity numbers $(G I N)$ was taken from the study of two situations: the first, by back analysis of the consumption of cement in the grouting holes (primary, secondary, tertiary and occasional); the second situation was the prediction of the intensity based on the results of EPA tests on interleaved primary holes (spacing of $24 \mathrm{~m}$ ).

The evaluation of the two case studies showed that the GIN curves generated by estimation were closer to the literature results cited by Gama (2012), Oliveira et al. (2001), and the authors of the GIN methodology, Lombardi \& Deere (1993). However, Lopes \& Assis (2016) evaluated the foundation rock mass of Jirau HPP spillway and affirmed that it had good hydraulic characteristics, even before grouting treatment, indicating that the region does not present wide-aperture discontinuities and does not require high consumption of cement grout and pressures, and thus the curves generated by back analysis are more coherent for adoption.
Another important factor in the choice of GIN curves is that the differences in intensities when compared (back analysis $v s$. estimation) are very high, besides the amount of dispersion points adopted for the estimation method is small and does not represent an effective foundation. For this reason, conservatism was chosen, with intensities determined by retroactive analysis and below the standards proposed by Lombardi \& Deere (1993).

In choosing the ideal dosage for the injection project, the cement mixtures used at Jirau HPP are within the stability criteria cited by Brandão (2014). Considering that $80 \%$ of the holes were injected with $w / c$ ratio of $0.7: 1$, in the application of the GIN methodology, it would not be necessary to thicken and change to the $w / c$ ratio of $0.5: 1$, only change in the pressures and curve volumes.

It is further noted that the Lombardi \& Deere GIN indication was determined for a water absorption ratio by $\mathrm{Lu}-$ geon tests, where $1 \mathrm{Lu}$ equals a conductivity of $10^{-5} \mathrm{~cm} / \mathrm{s}$. The pressure used in injection in most of the projects cited by the authors adopts the European practice, with values higher than those indicated in Brazilian projects. Thus, the boundaries of the guide curves may not be representative of the Brazilian scenario, and the type of the rock masses may differ.

Therefore, it is suggested that the study of the application of the GIN methodology in Brazilian projects continue to advance, aiming to improve and elaborate the guide curves for each base material found, correlating them with the EPA results. And, as mentioned in the work of Carvalho et al. (2003), the GIN has technical and operational advantages to be implemented in Brazil, and its studies must be continued.

\section{Acknowledgments}

To Energia Sustentável do Brasil (ESBR) and to Construções e Comércio Camargo Corrêa (CCCC) fors the release of the project and execution data to this research.

\section{References}

Brandão, A.C.M. (2014). Tratamento de Fundações da Barragem do Escalão Principal do Baixo Sabor. Dissertação de Mestrado, Universidade do Porto, Porto, 110 p.

Carvalho, E.; Filhote, F.P.T.; Leite, L.C.M.; Domingos, J.R.C.; D’Armada, J.C.R.; Freire Júnior, A.; Martorelli, E.A.; Souza, L.L.; Muniz, F.C.; Scarpin, S.E. \& Iañes, J.M. (2003). Execução do vertedouro complementar da UHE Marechal Mascarenhas de Moraes. Proc. XXV Seminário Nacional de Grandes Barragens. Salvador, 9 p.

Chiossi, N. (2013). Geologia de Engenharia. Oficina de Textos, São Paulo, 424 p.

Comitê Brasileiro de Barragens (2011). A História das Barragens no Brasil - Séculos XIX, XX e XXI: Cinquenta Anos do Comitê Brasileiro de Barragens. Comitê Brasileiro de Barragens, Rio de Janeiro, 553 p. 
Costa, W.D. (2012). Geologia de Barragens. Oficina de Textos, São Paulo, 352 p.

Cruz, P.T.; Manterón, B. \& Freitas, M. (2009). Concrete face rockfill dams. Oficina de Textos, São Paulo, 360 p.

Gama, P.S. (2012). Injeção de Caldas de Cimento em Fundações Rochosas de Barragens: Revisão Crítica de Metodologias. Dissertação de Mestrado, Universidade Nova de Lisboa, Lisboa, 200 p.

Google Earth (2014). Disponível em http://www.googleearth.com Acesso em 02 de julho de 2014.

Governo do Brasil (2018). Matriz Energética. Disponível em

http://www.brasil.gov.br/noticias/meio-ambiente/2010 /11/matriz-energetica. Acesso em 04/12/2018.

Houlsby, A.C. (1990). Construction and Design of Cement Grouting. John Wiley \& Sons, New York, 466 p.

Levis, S.D. (2006). Verificação da Eficácia dos Sistemas de Vedação e Drenagem em Fundações de Barragens de Concreto. Dissertação de Mestrado, Universidade de São Paulo, São Carlos, 195 p.

Lombardi, G. \& Deere, D. (1993). Diseño y control del inyectado empleando el principio "GIN". In: Water
Power and Dams Construction - Traduzido por Ulrich Hungsberg. México, $35 \mathrm{p}$.

Lombardi, G (1996). Selecting the grouting intensity. Proc. $4^{\text {th }}$ International Water Power \& Dam Construction, Carshalton, Hydropower \& Dam International Jounal, v. 3, pp. 62-66.

Lopes, M.B. \& Assis, A.P. (2016). Análise da eficiência do sistema de vedação da fundação em granito de uma barragem de concreto. Proc. Simpósio Brasileiro de Mecânica das Rochas, Belo Horizonte,CBMR, 8 p.

Oliveira, F.F. (2002). Análise de Tensões e Estabilidade Global de Barragens de Concreto Gravidade. Dissertação de Mestrado, Universidade de Brasília, Brasília, $183 \mathrm{p}$.

Oliveira, D.V.; Calixto, R.J. \& Moraes, R.B. (2001). Injeção de cimento com monitoramento em tempo real. Proc. 24 $4^{\text {th }}$ Seminário Nacional de Grandes Barragens, Fortaleza, ABMS, pp. 257-270.

Oliveira, A.M.S.; Silva, R.F. \& Júnior, J.F. (1975). Ensaios de Perda D'água sob Pressão: Diretrizes. Boletim ABGE 02. ABGE/IPT, São Paulo, 16 p.

Warner, J. (2004). Practical Handbook of Grouting: Soil, Rock and Structures. John Wiley \& Sons, New Jersey, $720 \mathrm{p}$. 